\title{
La gestión de los valores públicos en asociaciones público-privadas concesionales
}

\author{
Managing Public Values in Public-Private Partnerships: Do Public Authorities Succeed?
}

Salvador Parrado y Anne-Marie Reynaers*

\begin{abstract}
Resumen: Utilizando el instrumento de las asociaciones público-privadas (APP) del tipo de contrato concesional, los gobiernos logran sus objetivos de política pública cuando delegan la responsabilidad sobre la construcción de infraestructura pública y la provisión de servicios a consorcios privados. Las APP, como instituciones híbridas, incorporan desafíos de agenteprincipal en la implementación de políticas públicas, dado que los agentes privados pueden tener diferentes metas a las de las burocracias. Los gobiernos deben encontrar formas de gestionar los consorcios privados para que implementen objetivos de política pública a pesar de la asimetría de información inherente en las relaciones principal-agente y en presencia de diferentes lógicas institucionales (conflictivas): Estado versus mercado. Es posible que los gobiernos no siempre tengan éxito en la superación de estos conflictos y su fracaso para lograr los objetivos de política pública declarados puede dañar los valores públicos, como la rendición de cuentas, la transparencia, la responsabilidad, la capacidad de respuesta y la calidad. Para determinar empíricamente en qué medida los gobiernos logran salvaguardar los valores públicos en las APP, se ha empleado un estudio de caso múltiple que involucra siete proyectos concesionales en España y los Países Bajos. El análisis demuestra que los gobiernos ejercen control sobre las operaciones de los consorcios privados y, en general, pueden dar cuenta de
\end{abstract}

*Salvador Parrado es profesor de la Universidad Nacional de Educación a Distancia (UNED) en el Departamento de Ciencia Política y de la Administración, Facultad de Ciencias Políticas y Sociología, C/ Obispo Trejo, s/n. Madrid, 28040. Tel: +3491398 7091. Correo-e: sparrado@poli.uned.es. orcid: https://orcid. org/0000-0001-6600-5515. Anne-Marie Reynaers es profesora ayudante doctora de la Universidad Autónoma de Madrid en el Departamento de Ciencia Política y Relaciones Internacionales, Facultad de Derecho, Edificio Ciencias Jurídicas, Políticas y Económicas-1ª planta, C/ Marie Curie, núm. 1, Ciudad Universitaria de Cantoblanco, Madrid, 28049. Tel: +3491 497 4162. Correo-e: : anne.reynaers@uam.es, orcid: https:// orcid.org/0000-0002-1749-1390.

Los autores aparecen en orden alfabético y ambos han contribuido de igual forma al manuscrito. Esta investigación ha sido financiada por el Ministerio de Ciencia e Innovación de España gracias a la ayuda CSO2016-77493-P-Valores públicos, profesionales y partenariados público-privados en el área de salud.

Artículo recibido el 29 de abril de 2019 y aceptado para su publicación el 10 de marzo de 2020.

Dor: http://dx.doi.org/10.29265/gypp.v30i1.826 
sus resultados y pueden imponer una "lógica" estatal. Sin embargo, esto no sucede desde el principio, y no todos los valores públicos se conservan simultáneamente.

Palabras clave: Asociaciones público-privadas, valores públicos, rendición de cuentas, transparencia, capacidad de respuesta, calidad.

Resumen: Using the policy instrument of public-private partnerships (PPPs), governments achieve their policy goals by delegating the responsibility for the delivery of public infrastructure and service provision to private consortia. PPPs, as hybrid institutions, embody principal-agent challenges in the implementation of public policies given that private agents may have different goals than bureaucracies. Governments need to find ways of managing consortia so that they implement policy goals despite inherent information asymmetry and in the presence of different (conflictual) institutional logics: state versus market. Governments might not always succeed in overcoming these conflicts and their failure to achieve avowed policy goals may harm public values such as accountability, transparency, responsibility, responsiveness, and quality. In order to empirically determine to what extent governments succeed in safeguarding public values in PPPs, a multiple case study involving seven DBFMO projects in Spain and the Netherlands has been employed. The analysis demonstrates that governments exercise control over the operations of the private consortia and, overall, can account for their results and are able to impose a state "logic". However, this does not happen at the outset, and not all public values are preserved simultaneously.

Keywords: private-public partnerships, public values, accountability, transparency, responsiveness, quality.

\section{INTRODUCCIÓN}

R rindar servicios públicos o infraestructura a través de asociaciones público1 privadas (APP) se ha popularizado en varios países. Algunos consideran que la cooperación con el sector privado o la implementación de técnicas administrativas del sector privado, ambas prácticas institucionalizadas en un tipo específico de APP conocido como contratos de diseño-construcción-financiamiento-operación-mantenimiento (DCFOM) o contratos concesionales, podrían dañar los valores públicos (Collins y Butler, 2003; Frederickson, 1999). Al contrario, varios estudiosos consideran que los valores públicos se pueden salvaguardar, o incluso fortalecer, a través del uso de técnicas administrativas del sector privado (como la gestión del desempeño), y de la colaboración con el sector privado (Hirsch y Osborne, 2000).

Las APP son un tema de estudio popular (Wang et al., 2018; Willems y Van Dooren, 2016; Lohmann y Rötzel, 2018; Hodge y Greve, 2017), al igual que los valores públicos (Nabatchi, 2012; Jørgensen y Bozeman, 2007; De Graaf y Paanakker, 2015). Sin embargo, la investigación sobre la relación entre APP y valores públicos es relativamente escasa. La mayoría de las contribuciones analizan un solo valor público en un único estudio de caso y en un solo país (Reynaers, 
2014; Reynaers y Grimmelikhuijsen, 2015), y la cantidad de estudios que examinan incluso un valor público es baja. Usando un análisis de redes sociales, Wang et al. (2018) demuestran que la coexistencia de valor público y APP es baja. Rendición de cuentas, por ejemplo, aparece una vez, y capacidad de reacción/renegociación, aparece dos veces, mientras que calidad, responsabilidad y trasparencia no surgen en absoluto en un metaanálisis de los artículos de mayor impacto en administración pública y ciencia política en los años recientes (Wang et al., 2018).

Los contratos DCFOM, como instrumentos a través de los cuales se implementan políticas públicas, incorporan la lógica de la burocracia de mercado que identifican Considine y Lewis (1999). Dicha lógica se basa en la competencia, en los contratos como forma de control y en el precio como eje del suministro de servicios. Los actores privados se encargan cada vez más de la implementación de políticas públicas (Havinga y Verbruggen, 2017). Varias generaciones de estudios de la implementación de políticas públicas (Howlett, 2019) han trabajado solamente con cadenas de implementación de actores burocráticos, aunque a veces de distintos niveles de gobierno. Los obstáculos de la paradoja de la implementación son bien conocidos a partir del estudio pionero de Pressman y Wildavsky (1984), pero hay una brecha en la bibliografía sobre cómo los actores privados deberían revertir los resultados de la implementación de políticas públicas para dar ventaja a los valores privados sobre los públicos. De manera excepcional, algunos estudios se han enfocado en la rendición de cuentas de burócratas privados versus la de burócratas públicos en la inspección de alimentos (Thomann et al., 2018), o en cómo la implementación de políticas públicas por parte de actores privados o híbridos cumple con los resultados (objetivos de desempeño) que se establecen en áreas de seguridad en alimentos, telecomunicaciones y suministro de agua (Thomann et al., 2016). En general, se necesita atender la insistencia de Koppell (2010) de incluir programas basados en el mercado al estudiar las políticas públicas, y este artículo trata de contribuir a llenar esa laguna.

La pregunta de en qué medida tienen éxito las autoridades públicas salvaguardando los valores públicos se puede enmarcar en términos de la teoría del agenteprincipal. En teoría, el principal se apoya en el agente para suministrar productos y servicios. Los principales enfrentan posibles problemas de incumplimiento y de comportamiento oportunista de los agentes debido a la asimetría de la información (Kiewiet y McCubbins, 1991), así como al involucramiento de distintas lógicas institucionales. La teoría del agente-principal ha sido un método común en los estudios sobre implementación (Howlett, 2019), aunque rara vez se aplique a actores privados como agentes de burocracias públicas. En este caso, ayuda a 
entender en qué medida los contextos institucionales privado versus público ayudan a guiar las acciones de los implementadores (Garrow y Grusky, 2012). Siguiendo el involucramiento institucional, perseguir los valores públicos de la "lógica estatal" ideal típica podría entrar en conflicto con la "lógica de mercado", que se enfoca en las ganancias y en la eficiencia privada (Thomann et al., 2016). La asimetría en la información del marco principal-agente, que se traduce en la implementación de políticas por parte de actores privados o híbridos, conllevaría al dominio del "mercado" sobre la lógica del "Estado". Si esto se aplica a los contratos DCFOM, una pregunta clave es si el gobierno puede superar la asimetría de información para salvaguardar los valores públicos e imponer la "lógica del Estado". En teoría, los contratos DCFOM ofrecen instrumentos que ayudan al gobierno a hacerlo. Monitorear el desempeńo, por ejemplo, podría dar transparencia, y la aplicación de descuentos financieros podría ayudar a proteger la calidad del servicio, por mencionar algunos valores. Para saber cómo y en qué medida los gobiernos logran salvaguardar los valores públicos, aquí se analizan 112 entrevistas hechas entre 2012 y 2018 sobre siete contratos DCFOM.

El resto del texto se estructura de la siguiente manera. Primero explicamos los rasgos centrales de la teoría del agente-principal, después de lo cual analizamos el debate académico sobre la preservación de los valores públicos. Definimos los cinco valores seleccionados, a saber, rendición de cuentas, transparencia, capacidad de respuesta, responsabilidad y calidad. La sección metodológica considera la selección de casos, la recopilación de información y el análisis de datos. La sección de resultados evalúa, para cada valor, cómo y en qué medida el comprador ayudó (o no) a salvaguardar valores públicos. En la sección de discusión y conclusión, reflexionamos sobre las implicaciones de nuestro estudio en términos teóricos y prácticos.

\section{LA SALVAGUARDA DE LOS VALORES PÚBLICOS}

\section{Teoría del agente-principal}

Los agentes que trabajan ya sea en organizaciones privadas o como servidores públicos, tienen un nivel de discrecionalidad considerable para lograr el objetivo político que deben implementar. La teoría del agente-principal señala algunas de las debilidades para conseguir una implementación eficiente de objetivos de políticas públicas. Ante dos lógicas (Estado vs. mercado) (Thomann et al., 2016), el "propietario" que represente al Estado debe superar los obstáculos clásicos de la cadena principal-agente y los conflictos en torno a las metas que pueden tener los actores del sector público y del privado, como señaló Matland (1995). 
La teoría del agente-principal reúne los conceptos de delegación y de control político (Kiewiet y McCubbins, 1991) y se ha usado para analizar los contratos DCFOM, pero de manera limitada (Wang et al., 2018). A través de un acuerdo contractual, el agente opera en nombre del principal. Esa delegación se caracteriza por una asimetría de información, dado que el agente está mejor informado que el principal sobre el suministro real del servicio. Por lo tanto, el agente puede tener un comportamiento oportunista y explotar la información a su favor. Ese oportunismo podría aumentar si hay incentivos para que el agente actúe contra las preferencias del principal (Kiewiet y McCubbins, 1991).

El principal actúa de manera unilateral y elige "los mejores incentivos o mecanismos de supervisión para promover sus objetivos" para influir en las respuestas del agente (Carpenter y Krause, 2014: 9), y tiene una influencia considerable en el diseño institucional, pues puede intervenir en el arreglo de la estructura burocrática (y en el contrato), además, puede tratar de limitar el poder del agente (Moe, 1989). Se espera que los incentivos económicos y las estructuras de gobierno alineen los objetivos del principal y del agente (Eisenhardt, 1989) y motiven a los agentes a actuar en la dirección "correcta" (Hill y Jones, 1992: 132). Una estrategia de control orientada a la gestión es parte de este marco (Davis, Schoorman y Donaldson, 1997: 34). Su diseño elimina la necesidad de construir confianza entre los actores. A través de los incentivos financieros (pago del canon de disponibilidad en caso de cumplimiento, y deducciones, o penalizaciones, en caso de incumplimiento), el principal puede guiar las actividades del agente hacia el cumplimiento de las cláusulas contractuales. Reportes de monitoreo y reuniones periódicas con el principal, auditorías externas y evaluaciones son elementos que facilitan el control y la verificación continua de la actividad del agente.

En las situaciones mercantiles, donde hay contratos que regulan la relación entre el principal y el agente, es probable que la implementación de políticas públicas responda al modelo de "implementación administrativa" (poco conflicto y poca ambigüedad política) según la matriz desarrollada por Matland (1995). Sin embargo, dado el potencial inherente de conflictos por las diferentes lógicas (Estado versus mercado), este modelo puede evolucionar hacia el modelo de implementación política (mucho conflicto y poca ambigüedad). Como en el estudio de Thomann et al. (2016), nuestros supuestos centrales son que los agentes privados que implementan políticas públicas den prioridad a la "lógica de mercado" y que se creen conflictos sobre la interpretación de valores públicos en la implementación de políticas públicas. 


\section{Valores públicos en contratos de DCFOM}

Van der Wal (2008: 11) define los valores como "cualidades o normas que tienen cierto peso en la elección de acciones". En relación con el adjetivo "público", Reynaers y de Graaf (2014: 121) se refieren a esos valores que empírica o normativamente se considera que pertenecen al sector público. Beck Jørgensen y Bozeman (2002) proponen una selección de valores públicos basados en su importancia relativa en la literatura especializada. Por lo tanto, este texto considera los valores de rendición de cuentas, transparencia, capacidad de respuesta, cumplimiento de contrato (responsabilidad) y calidad (Beck Jørgensen y Bozeman, 2007; Bevir, 2010; Skelcher, Mathur y Smith, 2005).

La rendición de cuentas es una relación social en la que un actor se siente obligado a explicar y justificar su conducta a terceros (Mulgan, 2003; Bovens, 2007; Aucoin y Jarvis, 2005). Las autoridades públicas, por ejemplo, deben rendir cuentas ante el parlamento, los ciudadanos y otros foros por los gastos, los planes que han implementado y las decisiones que han tomado. En escenarios de contratos DCFOM, aunque se deleguen ciertas tareas a un consorcio privado, este no se escapa a la obligación de rendir cuentas. Así, el comprador debería seguir siendo capaz de rendir cuentas por el contenido del proyecto en términos financieros, legales y técnicos, y por el desempeńo real del consorcio privado durante todo el contrato (Reynaers, 2014). Se supone que el gerencialismo dificulta la rendición de cuentas, ya que la autoridad de tomar decisiones se transfiere parcialmente a compañías privadas. Si el contrato no prevé la necesidad de una "explicación" del agente, el comprador no puede hacer una buena rendición de cuentas. Al contrario, algunos esperan que las App ofrezcan marcos de rendición de cuentas más estrictos que los de muchas organizaciones públicas (Flinders, 2010; Willems, 2014). La evidencia empírica indica que la rendición de cuentas podría ser mayor en ciertas estructuras del sector privado a través de a) la introducción de un monitoreo sistemático del desempeño del agente; $b$ ) la especificación del nivel de servicio que debe conseguirse, y $c$ ) la aplicación de penalizaciones contra el incumplimiento (Domberger y Jensen, 1997: 76).

En este estudio, transparencia se refiere a la disponibilidad y precisión de la información sobre los aspectos legales, financieros, técnicos y operativos del proyecto (Reynaers, 2014), y se relaciona con la disponibilidad y acceso a la información sobre los costos de proveer el servicio público, los acuerdos y el desempeño conseguido (Acar y Robertson, 2004). Algunos autores (Papadopoulos, 2007; Hodge, 2004; Altshuler y Luberhoff, 2003) señalan que la transparencia puede ser deficiente debido a la falta de interés de los funcionarios públicos o a informa- 
ción inadecuada por parte del consorcio, ya sea para evadir el control o por la confidencialidad de los contratos. Reynaers y Grimmelikhuijsen (2015) presentan una visión más equilibrada y señalan que la transparencia depende de la claridad con la que se especifican en el contrato los requerimientos para reportar resultados.

La capacidad de respuesta se refiere a la reacción de las autoridades públicas ante las preferencias y las necesidades de los ciudadanos (Andrews y Van de Walle, 2012). En relación con los contratos DCFOM, se refiere a la capacidad del comprador de adaptar y renegociar las cláusulas contractuales para ajustar las necesidades cambiantes de una administración o de la sociedad en general. La limitada investigación empírica muestra que los ciudadanos y los consumidores de servicios perciben que la capacidad de respuesta en cuanto a servicios públicos ha disminuido en contextos gerenciales (Andrews y Van de Walle, 2012: 9). En el caso de los contratos de largo plazo, ciertos académicos afirman que la capacidad de respuesta del comprador disminuye, pues los gobiernos no pueden ajustar en retrospectiva los acuerdos contractuales con facilidad. Los gobiernos entrantes asumen los contratos y decisiones de sus predecesores, que pueden ya no reflejar el nuevo contexto socioeconómico ni las necesidades públicas cambiantes (Hodge y Greve, 2007).

Responsabilidad, o cumplimiento de contrato, se refiere al grado en el que el comprador hace que el consorcio cumpla con los acuerdos contractuales. Varios estudiosos se preguntan si ahora los gobiernos se consideran liberados de su responsabilidad pública, por haberla puesto en manos de la acción privada, y si pueden controlar suficientemente dicha acción (Debicki, 2003). Brown, Potoski y Van Slyke (2010) demuestran que el grado en el que los contratos garantizan que la responsabilidad pública se ejecute como se debe depende en gran medida de la integridad o de la calidad del contrato. En el contexto de los contratos DCFOM, Hood y McGarvey (2002) ilustran el oportunismo de las partes contratantes, que se culpan mutuamente y eluden la responsabilidad. Child, Faulkner y Tallman (2005: 55) añaden que la responsabilidad misma puede estar en riesgo y que ese riesgo es incluso mayor cuando hay múltiples socios privados involucrados.

La calidad denota el grado de satisfacción del comprador con la infraestructura y con su operación (Bovaird y Löffler, 2003). Se supone que la privatización, la contratación, las concesiones y las ApP mejoran la eficiencia y la calidad del suministro de servicios debido a la participación de compañías privadas y al uso de herramientas como la gestión basada en el desempeño. Al mismo tiempo, Box (1999) afirma que las compañías privadas buscarán ganancias financieras precisamente a costa de la calidad. Esto se debe al supuesto de que las compañías 
privadas se enfocan más en la productividad que en la calidad, dado que la primera es más fácil de medir (Holmstrom y Milgrom, 1991). Esto también se puede atribuir al uso de contratos incompletos que no pueden especificar el nivel de calidad requerido a largo plazo ni para todos los servicios. King y Pitchford (1998) indican que las dificultades de medición permitirían que el agente disminuyera la calidad sin que el principal lo detectara.

\section{METODOLOGÍA}

Realizamos un estudio de caso múltiple que incluye siete proyectos DCFOM en España y Países Bajos para elucidar si los hallazgos son específicos de cada caso o si se repiten en otros casos (Eisenhardt y Graebner, 2007: 27). Cinco de los siete contratos DCFOM prestan servicios públicos: un hospital con servicios clínicos y no clínicos bajo un contrato DCFOM (a partir de ahora lo llamaremos "el hospital clínico"), dos hospitales que proveen sólo servicios no clínicos (a partir de ahora los llamaremos "hospitales no clínicos"), un centro de detención y un ministerio. Los otros dos proyectos son de infraestructura: una carretera y una planta de purificación de agua. Dado que la interacción directa entre el agente y el principal es continua en las instalaciones de servicios públicos y más limitada en los proyectos de infraestructura, esperamos que la autoridad contratante se comporte distinto en cada caso. Los servicios que se brindan a través de los siete contratos DCFOM son de distinta naturaleza. Mientras que los agentes de los hospitales no clínicos, del centro de detención y del ministerio brindan sólo servicios secundarios (como limpieza y alimentación), los consorcios privados del hospital clínico, de la carretera y de la planta de purificación de agua ejecutan tareas organizativas primarias: cuidados médicos, mantenimiento de rutas y purificación de agua. Dadas las dificultades inherentes y la mayor amplitud de las tareas de estos últimos, esperamos ver variaciones en la forma en que la autoridad (el comprador público) controla al agente.

Analizamos datos cualitativos de 112 entrevistas (véanse Apéndice I para la guía de entrevistas y cuadro 1 para la distribución de los entrevistados) realizadas entre 2012 y 2018. Para el análisis, usamos MAXQDA (véase Apéndice II para el árbol de código). En cada proyecto, se hicieron entrevistas a actores que trabajaban ya sea para el comprador público o para el consorcio privado, o a asesores externos que podían trabajar para cualquiera de los dos. Las entrevistas tuvieron una duración promedio de una hora y se transcribieron textualmente. La selección de entrevistados siguió la técnica de muestreo de bola de nieve en todos los casos (Guest, Bunce y Johnson, 2006: 62). 
CUADRO 1. Cantidad de entrevistados por caso

\begin{tabular}{lccccccc}
\hline & $\begin{array}{c}\text { Hospital } \\
\text { clinico } \\
\text { núm. } 1\end{array}$ & $\begin{array}{c}\text { Hospital } \\
\text { clínico } \\
\text { núm. } 2\end{array}$ & $\begin{array}{c}\text { Hospital } \\
\text { no clinico }\end{array}$ & $\begin{array}{c}\text { Centro } \\
\text { de } \\
\text { detención }\end{array}$ & $\begin{array}{c}\text { Ministerio } \\
\text { de }\end{array}$ & $\begin{array}{c}\text { Carretera } \\
\text { Finanzas }\end{array}$ & $\begin{array}{c}\text { Planta de } \\
\text { purificación } \\
\text { de agua }\end{array}$ \\
\hline Autoridad & 10 & 8 & 15 & 9 & 10 & 12 & 4 \\
Consorcio privado & 3 & 0 & 4 & 2 & 8 & 5 & 5 \\
Asesores externos & 3 & 0 & 3 & 0 & 7 & 1 & 3 \\
Total & 16 & 8 & 22 & 11 & 25 & 18 & 12 \\
\hline
\end{tabular}

Fuente: Elaboración propia.

\section{HALLAZGOS: CONTROL RELATIVAMENTE ALTO SOBRE LOS CONTRATOS DCFOM}

\section{Mayor rendición de cuentas que en el suministro directo de servicios}

El comprador público no siempre es capaz de rendir cuentas por el contenido del propio acuerdo contractual. En algunos casos, la autoridad depende ampliamente de la asesoría legal y financiera externa. La falta de experiencia, habilidades o tiempo obligaron al comprador público a contratar asesores para manejar la complejidad legal, técnica y financiera de los contratos. Depender de consultores externos y de su involucramiento durante el tiempo del diseño del contrato y la fase de renegociación parece haber dificultado la rendición de cuentas. Para los funcionarios públicos fue difícil entender los acuerdos, reglas y mecanismos financieros. Esa pérdida en rendición de cuentas se superó en los casos del Ministerio de Finanzas y de los dos hospitales gracias a un comprador proactivo que asumió el liderazgo e interactuó constantemente con los asesores externos que se contrataron durante la fase de redacción del contrato. Un entrevistado dijo:

Durante la evaluación, las partes privadas nos dijeron que se habían sorprendido de lo profesionales que éramos. Pero lo habíamos preparado muy bien. Y siempre quisimos estar un paso adelante (director de proyecto, Ministerio de Finanzas).

Además, en el caso de los hospitales, el uso de asesores externos se consideró una prioridad para cumplir la exigencia política de firmar contratos simultáneamente para cinco y ocho hospitales en dos fases. La experiencia interna, aunque disponible, no podía tratar con una tarea tan demandante, y la fórmula financiera también representó un reto para los abogados estatales. 
Al principio, el gobierno estaba contratando asesores externos para que les ayudaran con los contratos en siete hospitales. Después, contrataron consultores externos para monitorear todos los aspectos del contrato, incluida la construcción de infraestructura y el cumplimiento de los indicadores de desempeño durante la fase operativa (asesor externo de siete hospitales).

La duración del proyecto, junto con el involucramiento de muchos actores durante una fase específica de la concesión y la pérdida resultante de continuidad, obstaculizaron la rendición de cuentas de largo plazo. En la mayoría de los contratos DCFOM, la "memoria del proyecto" se perdió con la salida de los miembros participantes. En el proyecto del centro de detención, por ejemplo, durante la preparación del proyecto se involucró muy poca gente a cargo de la operación. Esos profesionales salen de la organización inmediatamente después del cierre del contrato y dejan información limitada sobre la preparación del proyecto y el diseño del contrato. Un entrevistado mencionó algo común a todas las concesiones:

Lo engańoso es que tú haces acuerdos en una fase temprana. Luego, cada quien se va por su lado. Hay poca gente constantemente involucrada y eso es retador porque tienes ciertas ideas y tratas de ponerlas en papel, pero eso no significa que se adapten perfectamente a lo que está en el contrato (director de proyecto, centro de detención).

El conocimiento, necesario para exigir cuentas, desaparece de la organización junto con los actores clave. Este problema se puede superar cuando los implicados en la fase de adquisición siguen vinculados al contrato. La rendición de cuentas también se puede fortalecer cuando la información durante la fase de adquisición se comparte con los actores responsables de la operación de la concesión.

Todos los casos demostraron que los mecanismos de monitoreo no siempre funcionaron como se esperaba en la fase inicial de la operación del servicio. Esto de inicio obstaculizó la capacidad del comprador público de rendir cuentas de los gastos y del desempeño del consorcio. El mal funcionamiento de los mecanismos de monitoreo fue resultado ya sea de los errores de diseño o de la mala implementación. Inicialmente, en algunos casos holandeses, hubo ausencia completa de mecanismos de monitoreo. Un entrevistado reveló lo siguiente:

Al principio, no podíamos explicar exactamente lo que se hacía ni a dónde iba nuestro dinero. Pero eso tenía que ver con que era la primera vez que hacíamos algo así. Así que todavía se tenían que ajustar todos esos mecanismos (director de contratos, carretera). 
Sin embargo, cuando se implementaron esos mecanismos, según todos los entrevistados, el uso de auditores externos y el empleo más intensivo de inspectores de la autoridad relevante hizo que el comprador público tuviera una mejor rendición de cuentas sobre el desempeño de un contrato DCFOM que sobre el del suministro directo del servicio. En este último, esos mecanismos están más limitados o, incluso, ausentes. Con respecto a los servicios clínicos, uno de los hospitales estuvo sujeto a los mismos contratos de gestión que el resto de los sistemas de salud y esto aseguró niveles similares de rendición de cuentas.

\section{Los mecanismos financieros no son transparentes, pero dan más información sobre el desempeño}

La transparencia es impulsada fundamentalmente por la necesidad de revelar en el contrato todo lo que se va a medir y evaluar durante su vida. Esto requiere un trabajo detallado que también tiene la virtud —o la desventaja- de subrayar los errores incluidos en las cláusulas. En general, no es un problema. Si se detectan anomalías, se pueden hacer cambios al contrato, dado que el acuerdo con el consorcio privado se compensa en términos financieros. Debido al largo plazo de los proyectos y al uso del pago relacionado con el desempeño, la autoridad debe determinar y establecer los aspectos financieros, jurídicos y técnicos del proyecto antes de iniciar las operaciones.

El uso de especificaciones sobre los resultados disminuye la transparencia inicial del proceso, aunque la aumenta en los resultados. La pérdida de transparencia inicial del proceso se puede compensar. De hecho, muchos compradores suelen incluir cláusulas con especificaciones iniciales detalladas que no dan pie a interpretaciones por parte del consorcio. Las especificaciones de los resultados muchas veces contienen normas cualitativas (las superficies deben estar limpias) y estándares cuantitativos (un carril de carretera no se puede interrumpir durante más de una hora). Mientras que las normas cualitativas que son difíciles de medir pueden reducir la transparencia de las especificaciones para el resultado, las normas cuantitativas contribuyen a la transparencia de las especificaciones. Esto se demostró en los casos de la planta de tratamiento de agua, la carretera y los hospitales. Las interacciones constantes a través del monitoreo ayudaron en todos los casos a fortalecer la transparencia de las especificaciones iniciales y de resultados. Un entrevistado de la planta de purificación subrayó:

En [nombre de la compañía] es mucho más objetivo [que en un proyecto donde se usan especificaciones cualitativas para el resultado]. La gente mide la calidad de las aguas resi- 
duales que entran y miden lo que sale. Eso es cuantitativo. Esas mediciones las revisa un inspector independiente cada seis meses. Sello. Firma. Satisfecho. Esos números se procesan en un reporte. [Nombre de la compañía] entrega un reporte técnico cada mes. Demuestra lo que hemos hecho: si retiramos el nitrógeno, los materiales sueltos, cuántas bombas fallaron y qué requisitos ya cumplimos. Eso es meramente técnico. La junta del agua puede revisar eso y solicitar cualquier tipo de información en cualquier momento (director general, consorcio privado).

En consonancia con eso, un entrevistado del hospital no clínico describió:

Es un proceso transparente. Mandamos varios reportes cada mes. Por ejemplo, lavamos toda la ropa y mandamos un recibo que indica cuántos kilos se lavaron. Todo eso lo monitorea una unidad técnica subcontratada por el gobierno. El comprador público y nuestra compañía también tienen representantes en esa unidad para hacer el monitoreo (director, hospital no clínico).

La creación de modelos financieros no es de fácil comprensión para los que no tienen las habilidades necesarias, y aunque eso pueda limitar la transparencia, los compradores ya conocen el costo de los servicios, algo poco común en el suministro directo de servicios. Por lo tanto, en este aspecto hay mucho mayor transparencia financiera. El problema es que en el sector público normalmente no tienen integrada la capacidad de entender esos modelos financieros.

La planeación financiera de largo plazo ofrece transparencia en el sentido de que, con excepción de los costos variables, el comprador sabe cuánto dinero se va a gastar durante los próximos veinte o treinta ańos. Sin embargo, algunos casos demuestran que lo que se compra con ese dinero no es tan transparente, pues las comisiones de disponibilidad incluyen costos pasados, actuales y futuros. Los casos de la carretera y del centro de detención mostraron que el comprador paga por el reemplazo de ciertos artículos en el futuro, aunque el consorcio no garantice que efectivamente se harán esos reemplazos.

Dices que algo tiene una vida útil de cinco años y el contrato dura veinte, así que [el consorcio] debe reemplazarlo cuatro veces. El consorcio calcula un precio para el reemplazo, pero no quieren hacer acuerdos explícitos sobre el reemplazo real (director de proyecto, centro de detención).

Sin embargo, en hospitales con contratos DCFOM, los artículos se tienen que reemplazar inmediatamente, mientras que los hospitales públicos tradicionales tienen mobiliario y equipo vetusto y dańado. Aunque el porcentaje del canon de 
disponibilidad es trasparente, pues se establece por escrito lo que se pagará, la precisión de las cifras fue cuestionable en todos los casos holandeses. Además, los proyectos del centro de detención y de la carretera revelaron que el comprador no siempre quedó satisfecho con el nivel de transparencia que ofreció el consorcio cuando se trataba de valorar trabajo adicional. En algunos casos holandeses no siempre está claro si el cargo refleja los precios de mercado o si el consorcio incluyó costos relacionados con riesgos que ya se habían pagado en la licitación inicial. En el proyecto del centro de detención, el comprador público se preguntaba si su propia organización sabía si había ahorrado dinero o no. En los hospitales, como hubo relativamente pocos cambios que exigieran inversión o compra de material adicionales, los entrevistados no expresaron ninguna sorpresa al respecto.

Monitorear el desempeño y reportárselo al comprador parece aumentar la transparencia en comparación con el suministro directo de servicios, donde muchas veces no existe tal monitoreo. Sin embargo, lograr una transparencia real depende del diseño y la implementación del plan de monitoreo.

En todos los casos holandeses, el consorcio privado entrega el reporte de monitoreo al comprador. Fuera del proyecto del agua, la precisión de los reportes no se pudo garantizar. Las discrepancias ocasionales entre los reportes de desempeño que produjo el consorcio y los que entregó el comprador señalaron la necesidad de medidas adicionales o de evaluaciones externas. En el caso del proyecto del agua, el consorcio no estuvo dispuesto a ofrecer la transparencia solicitada para establecer confianza y buena reputación. Finalmente, aunque los reportes de monitoreo de desempeńo den transparencia, la enorme cantidad de papeleo fue difícil de procesar y, en el caso de la carretera, por ejemplo, se consideró que el papeleo entorpeció la transparencia.

En los hospitales, el contrato permitió un periodo inicial de seis meses donde no se aplicaron deducciones ni sanciones. Durante esa fase se definió el instrumento de monitoreo. A diferencia de los casos holandeses, un tercero (otro contratista del comprador) fue responsable de reportar el incumplimiento en los hospitales. Además, en los contratos DCFOM donde solo se contrataron los servicios no clínicos, el personal de salud supervisa el proceso de quejas por incumplimiento. El consorcio privado tiene que arreglar el problema, de lo contrario, se aplica automáticamente una deducción al canon de disponibilidad. Aunque hay discusiones sobre el uso de ciertos indicadores de desempeño y de su interpretación, el sistema es altamente transparente para ambas partes contractuales. Para los servicios clínicos, el hospital está sujeto a un sistema de monitoreo genérico para efectividad clínica y calidad percibida. Está sujeto a mecanismos de transparencia 
similares a los del resto de los hospitales públicos: reuniones de monitoreo bilaterales y la publicación en línea de información sobre desempeño.

\section{Los contratos de largo plazo no tienen capacidad de respuesta inmediata ante los retos sociales}

Como los cambios contractuales o la adaptación de estándares de desempeño tienen un efecto inmediato en el modelo financiero e implican una carga administrativa y financiera, los cambios deberían evitarse lo más posible. Ser prudentes con respecto a los cambios contractuales podría implicar una disminución en la capacidad de respuesta, pero, en los cuatro casos holandeses, el contrato y los estándares de desempeño estuvieron sujetos a cambios constantes, dado que la legislación es relativamente laxa al respecto. Los hospitales españoles enfrentan mayores restricciones sobre las cláusulas de renegociación, pues la ley de contratos tiene reglas rígidas sobre los cambios solicitados por cualquier parte. La renegociación podría alterar el precio final, y eso socavaría el principio de competencia justa bajo la cual se concedió el contrato.

A pesar de la posibilidad de cambios en el contrato y en las especificaciones de los resultados durante cualquiera de las fases del proyecto, en ninguno de los cuatro casos holandeses el comprador sintió que estuviera "al mando" del proyecto. En el caso del centro de detención, por ejemplo, el comprador dijo que dejó de sentirse el jefe en su propia casa: "Sientes que tienes las manos atadas en tu propia casa" (director, centro de detención).

Este sentimiento no se expresó al discutir los proyectos de hospitales. Puede haber ayudado el hecho de que la mayoría de los directivos por parte de la autoridad y del consorcio son médicos que entienden lo que se puede hacer en términos clínicos (para los contratos DCFOM clínicos) y qué servicios se requieren del consorcio privado.

Todos los cambios solicitados por los compradores están sujetos a negociaciones a veces largas y costosas que evitan que se satisfaga la demanda de manera directa. Además, la contratación integrada de largo plazo no da espacio de maniobra cuando el comprador público quiere recortar sus costos. El plan de negocios del consorcio calcula las ganancias con base en el contrato inicial y en las especificaciones de resultados. Por lo tanto, el comprador público no puede reducir el canon de disponibilidad a voluntad. Un entrevistado nos dijo:

El gobierno central decidió recortar presupuestos. Así que tuvimos que elegir las vías principales para decidir a dónde iría el dinero. En mayo se decidió que todas las vías del norte 
tenían que apagar la luminaria. Normalmente, diríamos: "luces apagadas; menos consumo; menos gasto". Pero no funciona así con los contratos DCFOM. Tenemos un contrato y cuando el consorcio nos dice que no se ha cobrado nada por iluminación, entonces no podemos ahorrar nada de ahí. Debemos pagar la cantidad establecida previamente (directores de contratos, carretera).

La naturaleza de largo plazo del contrato que establece los parámetros legales, financieros y técnicos del proyecto por todo el tiempo que dure también limita la influencia política. En el caso de la planta de tratamiento de agua, por ejemplo, los políticos de la Junta de Agua no podían introducir sus propias preferencias al inicio de un nuevo periodo. Aunque eso se percibió como positivo en términos de continuidad del contrato DCFOM, los miembros de la junta aceptaron con dificultad que su influencia en el proyecto hubiera disminuido. En el caso de la carretera, el acuerdo contractual entre la administración y el consorcio excedió el alcance territorial de la provincia donde se había construido. Esto redujo el espacio de maniobra de los políticos locales y de los gestores públicos. Desde que iniciaron los contratos DСFOM en los hospitales ha estado en el poder el mismo partido político, y en esos casos los políticos no han solicitado ningún cambio en los contratos, según los entrevistados.

\section{Se cuestiona la responsabilidad de la administración}

En general, los consorcios privados tienden a hacer lo que se pide en el contrato, pero varios factores crean obstáculos. Tanto las cláusulas del contrato como los estándares establecidos deberían indicar las responsabilidades precisas del consorcio privado. Pero muchas veces son ambiguas o incompletas, y dan pie a discusiones entre el comprador y el contratista sobre su interpretación. Esas discusiones son más constructivas en algunos proyectos que en otros, pero no encontramos patrones claros en las razones de opiniones divergentes. En uno de los hospitales, el consorcio fue a los tribunales a resolver la disputa, pero eso sucede en la minoría de los casos.

En algunos hospitales, como [nombre de los hospitales], los directores del consorcio no estaban de acuerdo con los indicadores ni con las deducciones de las comisiones. En consecuencia, fueron a los tribunales. Sin embargo, esto solo sucede en 10 por ciento de los casos (asesor externo que trabajaba en la unidad de monitoreo para varios hospitales).

Las compañías del consorcio privado muchas veces no están de acuerdo en la asignación de responsabilidades internas. Salvo en la carretera, los consorcios 
privados se dividieron internamente en dos grupos: diseño y construcción, y operación y mantenimiento. Dada esta delimitación, la responsabilidad del grupo de diseño-construcción frente a los demás socios cesó en cuanto inició la fase operativa. Cuando las irregularidades derivadas de la fase de construcción empezaron a tener un impacto negativo en la operación, la compañía que prestó el servicio sufrió las consecuencias financieras, sobre todo en los casos holandeses. Un entrevistado dijo:

En la fase de diseńo [los miembros del consorcio] no comunicaron sus intereses de antemano. Por ejemplo, usaron pintura blanca en los muros. Mucha gente pasa por ahí, así es que se dañan fácilmente. Y unos meses después, el director se quejó de que las paredes estuvieran sucias. Así que solicitaron que la compañía de limpieza lavara o pintara las paredes. Pero la compañía de limpieza dijo que era responsabilidad de la compañía de construcción por haber decidido usar esa pintura. Tienen un problema interno que se convierte en problema nuestro (director de proyecto, centro de detención).

Esto no fue evidente en los hospitales, pues las compañías crearon un consorcio donde el contratista principal, por lo general una compañía constructora en los contratos DCFOM no clínicos y un grupo de salud en el hospital clínico, subcontrataría los servicios operativos. Por lo tanto, aunque el contratista fuera técnicamente un conglomerado de compañías, una parte del consorcio privado era responsable de todo. Los gestores del lado de la autoridad muchas veces decían que nunca se tuvieron que preocupar por los problemas internos del consorcio pues el contrato DCFOM asignaba claramente las responsabilidades.

\section{Las APP entregan infraestructura de calidad}

Mientras que hay un alto nivel de satisfacción en los siete proyectos con respecto a la calidad de la infraestructura, no es el caso con los aspectos operativos de los proyectos. En el caso del centro de detención, la calidad de la operación fue muy decepcionante, excepto por el suministro de alimentos. Un entrevistado dijo:

En cierto momento, el servicio era tan malo que pagábamos mucho menos por el canon de disponibilidad. Pero no quiero ese dinero. Quiero un buen servicio (director de contratación, centro de detención).

Las irregularidades en la calidad de operación podían derivarse de la poca atención que se le puso a la fase de suministro de servicios durante la preparación del proyecto, a la ausencia de guías con respecto a cómo transitar de la construcción a la operación, o a la ambigüedad en las especificaciones sobre los resultados. En el 
caso del Ministerio de Finanzas, la mala calidad de la operación se atribuyó a la falta de atención en la fase operativa por parte tanto del comprador público como del consorcio durante las fases de preparación del proyecto y construcción, a la falta de comunicación sobre la fase operativa entre los socios del consorcio, a la falta de experiencia en suministro de servicios en el contexto de contratos DCFOM, y a la ambigüedad de las normas. Sin embargo, en los hospitales, el comprador estaba contento con el nivel de calidad operativa que evalúa mensualmente una comisión compuesta por el comprador, el consorcio privado y un tercero (privado).

El director ejecutivo de uno de los hospitales no clínicos dijo:

La calidad de este tipo de hospitales es superior a la de los hospitales tradicionales. El nivel de control, las auditorías y las inspecciones, junto con los incentivos económicos, los hace esforzarse por la calidad.

En el caso de la carretera y del proyecto de agua, la fase operativa fue menos problemática en términos de calidad. Aunque en el primero, las ambiguas especificaciones sobre los resultados llevaron a discusiones, la calidad del mantenimiento parece ser un impedimento sobre los proyectos tradicionales, gracias a las soluciones innovadoras y a la rápida resolución de problemas. En el proyecto del agua, el involucramiento directo de la compañía operadora en la preparación parece haber contribuido a tener resultados satisfactorios. En ambos casos, la relativa sencillez de la fase operativa y sus correspondientes criterios cuantitativos sobre el resultado pueden haber contribuido a la calidad del proyecto general. Finalmente, el relativo aislamiento ante la opinión de los usuarios durante la fase operativa parece haber tenido un efecto positivo en la percepción de la calidad. En los proyectos del hospital, el centro de detención y el Ministerio de Finanzas, los usuarios también juzgaron la calidad de la operación del servicio. Por ejemplo, sistemáticamente, los hospitales bajo contratos DCFOM arrojaron mayores niveles de satisfacción entre pacientes con respecto a la infraestructura, los servicios auxiliares y la atención clínica que en los hospitales que brindan servicios directamente (Parrado y Reynaers, 2018).

El pago relacionado con el desempeño, aplicado en los contratos DCFOM, en teoría ayuda al comprador a gestionar la calidad. Sin embargo, los casos demuestran que la efectividad de esta herramienta para fortalecer o mejorar la calidad no está garantizada automáticamente en los casos holandeses, pero es un impulso importante a las políticas de calidad en los hospitales. En los casos del centro de detención, el Ministerio de Finanzas y la carretera, las multas no siempre llevaron directamente a soluciones. La aplicación inconsistente de multas y la dificultad 
para calcular con precisión el nivel apropiado de la multa podría haber socavado su efectividad. Un entrevistado del Ministerio de Finanzas recalcó:

Hubo algunas multas, pero a veces el comprador no las usó. En cierto punto, las multas dejaron de funcionar. Entonces decidimos contratar a un mediador (miembro de proyecto, Ministerio de Finanzas).

En consonancia con esto, un director de contratación de la concesionaria del hospital clínico dijo:

Hubo casos absurdos. A veces nos decían, "hay un problema con un sobre de cola-cao [polvo de chocolate] y el paciente está desayunando", o algo así. Y nos podía costar, según el contrato, digamos $\$ 20000$ euros. Es absurdo. Si las multas no están bien diseñadas, puede haber situaciones extrañas (director de contratos, concesionaria del hospital clínico).

En los hospitales, los servicios clínicos y no clínicos son sensibles al pago relacionado con el desempeño. En los servicios no clínicos, las sanciones y las deducciones automáticas, incluso aunque fueran provocadas por la inconformidad del consorcio privado, ejercen presión continua para cumplir con los estándares requeridos por el contrato. Para los servicios clínicos, los estándares de desempeño para la efectividad clínica, la seguridad de los pacientes y la percepción de éstos sobre los servicios son parte de los contratos de gestión en todos los hospitales. Los contratos DCFOM no tienen problemas para cumplir las metas de esos contratos anuales, mismos que consideran un poco limitados y probablemente más adaptados a los hospitales públicos “ineficientes” (Parrado y Reynaers, 2018).

\section{CONCLUSIONES Y DISCUSIÓN SOBRE LOS RESULTADOS}

Los contratos DCFOM son instrumentos contractuales con los que los agentes privados implementan objetivos de políticas públicas. Dado que están atados por el contrato, se espera que puedan tener un nivel relativamente bajo de conflicto sobre los objetivos, y que dichos objetivos no sean ambiguos, como predice el modelo de implementación administrativa de Matland (1995). Sin embargo, los posibles conflictos sobre la salvaguarda de los valores públicos están en el centro de este texto cuando evaluamos la capacidad de los actores estatales de imponer la "lógica del Estado" sobre la del mercado (Thomann et al., 2016).

La respuesta a si las autoridades públicas pueden salvaguardar o incluso fortalecer los valores públicos a través de contratos DCFOM no es la misma para todos los valores públicos considerados. La respuesta también depende del tipo 
CUADRO 2. Condiciones que ayudan a salvaguardar los valores públicos

Amenaza los valores públicos

\begin{tabular}{|c|c|}
\hline 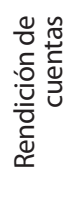 & $\begin{array}{l}\text { - Depender de asesores externos } \\
\text { - Discontinuidad en el involucramiento de } \\
\text { los actores } \\
\text { - Implementación o uso incorrectos de } \\
\text { mecanismos de monitoreo } \\
\text { - Naturaleza de largo plazo del contrato }\end{array}$ \\
\hline 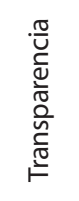 & $\begin{array}{l}\text { - Especificar los resultados (transparencia en } \\
\text { insumos) } \\
\text { - Normas cuantitativas } \\
\text { - Falta de experiencia financiera interna } \\
\text { - Diseño o implementación de mecanismos } \\
\text { de monitoreo inapropiados }\end{array}$ \\
\hline
\end{tabular}

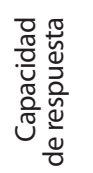

- Contratos inflexibles

- Externalización de servicios por parte del consorcio

- Naturaleza de largo plazo del contrato

- Ambigüedad de las especificaciones y cláusulas sobre resultados

- Débil asignación de riesgos por parte de consorcios privados

- Disputas internas (entre miembros del consorcio privado)

- Descentralización de las responsabilidades de gestión entre miembros del consorcio

- Ambigüedad en las especificaciones de resultados

- Escasa atención a la fase de suministro de servicios durante la preparación del proyecto

- Ausencia de guía para transitar de la construcción a la operación

- Falta de comunicación entre socios del consorcio sobre la fase operativa

- Falta de experiencia suministrando servicios en el contexto de contratos DCFOM

- Aplicación inconsistente de multas
Promueve los valores públicos

- Experiencia interna

- Hay continuidad de los actores en el diseño y la implementación del contrato

- Usar contratos de gestión de desempeño

- Monitoreo del desempeño

- Auditorías externas

- Adquisiciones proactivas

- Especificar los resultados (transparencia en los resultados)

- Normas cualitativas

- Modelos financieros de largo plazo

- Pago ligado al desempeño

- Monitoreo del desempeño

- Publicación de información sobre el desempeño en línea

- Contratos flexibles

- Cláusulas contractuales claras

- Centralización de las responsabilidades de gestión en el consorcio

- Usar criterios cuantitativos para resultados

- (Dar espacio para) proponer soluciones innovadoras

- Predisposición del consorcio privado para la resolución rápida de problemas

- Involucramiento de la compañía operadora en la fase de preparación

- Pago ligado al desempeño

Fuente: Elaboración propia. 
de relación entre el principal (el comprador) y el agente (el consorcio privado). Esa relación se basa en la idea de que se logran los resultados que desea el principal, de que el poder se delega al agente y de que la autoridad pública tiene control sobre el nivel de desempeño. El cuadro 2 resume las condiciones o instrumentos que ayudan a salvaguardar o que podrían perjudicar los cinco valores bajo escrutinio en este estudio.

Como primer instrumento para asegurar que el agente ejecutará las órdenes que se le dieron, el principal espera que el agente rinda cuentas por su trabajo. A su vez, el agente, más cercano a las fuentes de información, podría verse tentado a no rendir cuentas y asegurarse que la información no sea transparente. La teoría de la autoridad política no siempre se aplica perfectamente en los contratos DCFOM. Con respecto a la rendición de cuentas, los hallazgos indican que, aunque el contrato DCFOM ofrezca mecanismos suficientes para que los servidores públicos rindan cuentas, sus efectos reales dependen de cómo se usen dichos mecanismos (Flinders, 2010). El uso de tales mecanismos no siempre es óptimo. Con respecto a eso, es cierta la afirmación de Domberger y Jensen (1997: 76) de que la rendición de cuentas podría salvaguardarse mejor con estructuras de gobierno inspiradas en la Nueva Gestión Pública (NGP) gracias a la introducción de monitoreo sistemático del desempeńo, a la construcción y uso de especificaciones de nivel de servicios y a la aplicación de mecanismos que ayudan a prevenir el incumplimiento, o que lo penalizan con efectividad, pero solo si esos mecanismos se usan como deberían. Al comprador le toma cierto tiempo llegar a esa fase. Encontramos algunas diferencias entre Países Bajos y España. Primero, el principal corre el riesgo de perder cantidades considerables de información en los contratos DCFOM holandeses. Por un lado, el comprador recurre a asesores externos (sobre todo en Países Bajos), quienes controlan el sentido de las cláusulas financieras y legales. Al mismo tiempo, el consorcio y sus expertos maximizan su ventaja al negociar el contrato. Cuando sucede esto, el principal puede ejercer poca influencia. Segundo, el equipo de gestión del comprador cambia entre la negociación del contrato y la fase operativa, lo cual limita el grado de rendición de cuentas que se le puede exigir al comprador público por el contrato, su contenido y la forma de aplicarse.

La transparencia es esencial si el principal pretende ejercer control sobre el agente, porque minimiza la asimetría de información. Los resultados muestran dos posturas distintas. En los hospitales, el principal implementó un instrumento de control administrado por una unidad externa al consorcio y subcontratada por la autoridad pública. Esa unidad registra y controla la información sobre 
inconformidades por parte del personal de salud hospitalario. Esto contrarresta el monopolio potencial de información que podría ejercer el consorcio privado. Para servicios clínicos, el hospital bajo contrato DCFOM está sujeto a los mismos mecanismos de control que otros hospitales públicos, y el sistema publica información comparativa sobre el desempeño de todos los hospitales. Sin embargo, en los casos holandeses, el consorcio privado controla su propio desempeño e información. En ambos casos pueden surgir problemas de interpretación de resultados y el comprador hace auditorías, inspecciones o pruebas aleatorias para confirmar la información que le ofrece un agente privado.

La transparencia parece ser más fácil y, a veces, incluso mejorar en comparación con los sistemas tradicionales, pero a veces parece estar en riesgo. Los hallazgos no respaldan por completo las posturas de Bloomfield (2006) y Papadopoulos (2007), quienes afirman que las prácticas de la NGP disminuyen el nivel de transparencia. Los procesos de adquisición de los contratos DCFOM y la exigencia de monitoreo asegurarán el suministro de información sobre el proyecto. Sin embargo, la complejidad del sostén financiero del proyecto frustra la transparencia en el sentido de que aquéllos que deberían entender los acuerdos no siempre son capaces de entenderlos (Hood, Fraser y McGarvey, 2006). Además, los hallazgos muestran que la información no siempre está disponible ni es precisa (Altshuler y Luberhoff, 2003). Sin embargo, los consorcios ofrecen datos sobre el desempeño, y cualquier falta de información o la imprecisión de la misma no es estructural. Con el tiempo puede mejorar el suministro de información más precisa. Por lo tanto, la afirmación de que los contratos DCFOM promueven la generación de datos sin sentido (Hood, Fraser y McGarvey, 2006) no se sostiene en los hallazgos de estos casos.

Con respecto a la capacidad de respuesta, aparece una imagen ambigua. Aunque los servidores públicos ya no estén a cargo de la operación, su influencia se sigue sintiendo a lo largo de todo el contrato y de las especificaciones de los resultados, en la aplicación de los mecanismos de monitoreo y en los posibles ajustes del desempeńo. Por lo tanto, los hallazgos de este estudio no sustentan la afirmación de que el sector público deja de tener el control cuando se trata de influir y de llevar a cabo políticas públicas (Bevir, 2010; Flinders, 2010; Skelcher, 2010). En cambio, la influencia de las autoridades públicas en un contrato DCFOM parece haber cambiado, no declinado. Aunque ellos mismos no brinden los servicios, los compradores públicos actúan como prestadores y como coordinadores de proyecto, lo que indica que la red público-privada sigue "perteneciendo al gobierno" (McGuire y Agranoff, 2011: 279). Sin embargo, aunque los servidores 
públicos puedan redactar el contrato, definir las especificaciones para resultados y adaptar ambos documentos durante las fases de construcción y operación, las, a veces, lentas y costosas negociaciones previas a la adaptación no permiten que el comprador influya directamente en el desempeño del consorcio. En los casos españoles, hay restricciones considerables para introducir cambios. Además, la influencia actual de los servidores públicos depende del nivel de insumos y del papel exacto de los asesores externos, quienes, en algunos proyectos holandeses, no solo asesoraron al comprador, sino que también tomaron decisiones importantes. Todos los proyectos demuestran que los DCFOM constituyen instrumentos de despolitización gubernamental, como sucede en Flandes y en Reino Unido (Willems y Van Dooren, 2016). Esto en consonancia con la "lógica de la disciplina" donde el gobierno delega responsabilidades al sector privado por medio de una licitación para deshacerse de algunas propias (Jessop, 2014).

Bovaird (2004) afirma que las prácticas de la NGP vuelven menos probable que los políticos tengan capacidad de respuesta ante circunstancias cambiantes. Los resultados indican que su influencia ciertamente se ve obstaculizada cuando tratan de introducir cambios contractuales e implementar recortes presupuestarios, como también sugiere Hodge (2010). La naturaleza de largo plazo del contrato también parece disminuir la cantidad de influencia política en el proyecto.

Con respecto a la responsabilidad, los hallazgos de este estudio no respaldan la afirmación de Debicki (2003) de que las partes privadas podrían fallar completamente al tratar de ofrecer servicios públicos. A pesar de las irregularidades, los consorcios, en general, se desempeñan como deberían. Sin embargo, la ambigüedad de los contratos y de las especificaciones de resultados lleva a discusiones y crea la oportunidad de echarle la culpa al otro y de eludir responsabilidades (Hood y McGarvey, 2002; Brown, Potoski y Van Slyke, 2010). El grado en el que los contratos garanticen el cumplimiento dependerá sobre todo de la calidad y del detalle del contrato. Además de la importancia de la calidad del contrato y de las especificaciones sobre los resultados, el cumplimiento también depende de la actitud o de la disposición del consorcio.

Los resultados indican una satisfacción general con la calidad de la infraestructura. La calidad del servicio se presta a controversia, pero no hay indicios de que sea menor o disminuya, y esto difiere de estudios que reportan una reducción de la calidad (Hartley y Huby, 1986; Van Slyke y Hammonds, 2003). La calidad, ya sea de la infraestructura o del suministro de servicios, parece al menos mantenerse o, incluso a veces, mejorar, sobre todo en los hospitales, según estudios estadísticos. Esto está en consonancia con resultados empíricos previos 
en el contexto de contratación y privatización (Andaleeb, 2000; Fumagalli, Garrone y Grilli, 2007).

Los hallazgos apoyan la afirmación de Domberger y Jensen (1997) de que la calidad parece facilitarse, o incluso mejorar, gracias a la formulación de resultados y a la introducción de monitoreos de desempeño. Sin embargo, salvaguardar la calidad depende tanto de la capacidad del comprador público de traducir sus expectativas en resultados como de la capacidad del mecanismo de monitoreo de identificar lo que se debe ajustar para cumplir con las expectativas. Como sugieren Peat y Costley (2001), aplicar mecanismos de monitoreo y operar mecanismos financieros demostró ser problemático en todos los casos. Esto se puede atribuir a la falta de capacidad de gestión y al conocimiento deficiente de la lógica de adquisición específica (De Bettignies y Ross, 2009; Van Slyke y Hammonds, 2003), aunque ciertamente la calidad del monitoreo de contratos depende de la calidad de la organización pública o de los servidores públicos, cosa que puede variar de un contexto a otro (Domberger y Jensen, 1997). Además, en los casos del centro de detención, de los servicios de hospitales no clínicos y del Ministerio de Finanzas, la evaluación del desempeño con respecto a la operación fue más bien subjetiva y dio pie a diferentes interpretaciones que podrían haber estado sujetas a discusión (Domberger y Jensen, 1997). Finalmente, los proyectos de la carretera y la planta de agua demostraron que los criterios cuantitativos de resultados dan menos espacio a la interpretación y desatan menos discusiones sobre la calidad que ofreció el consorcio. Con respecto a los servicios clínicos, la existencia de contratos de gestión, el ranking de desempeño de hospitales y el claro entendimiento de los indicadores de desempeño que miden la efectividad clínica y la seguridad de los pacientes reducen las discusiones sobre el concepto de calidad. Cuando ocurren estas discusiones, también aplican para hospitales públicos. Los hallazgos apoyan la premisa de que, para salvaguardar la calidad, las expectativas de la autoridad deben estar articuladas con claridad, y el desempeño debe ser medible (Alonso y Andrews, 2016; Brown, Potoski y Van Slyke, 2006; Deakin y Walsh, 1996).

Los resultados de este estudio coinciden con investigaciones previas que enfatizan la importancia de que el contrato sea detallado (Brown et al., 2007; 2010) y de los administradores públicos que tienen la capacidad de aplicar adecuadamente las herramientas de calidad de gestión (Peat y Costley, 2001). En relación con lo detallado del contrato, los resultados muestran que las especificaciones incompletas o ambiguas del producto o servicio provocan controversias en relación con la calidad. Aunque los compradores públicos pueden gastar más tiempo si 
escriben especificaciones más detalladas o menos ambiguas, es muy poco probable que un contrato contenga especificaciones completas sin rastro de ambigüedad (Brown et al., 2010). Por lo tanto, el comprador debe ser consciente de las limitaciones inherentes a esos contratos.

Para la implementación de políticas públicas, el diseño del contrato (perspectiva de arriba abajo de implementación de políticas públicas) y el grado de discrecionalidad que se da a los agentes (implementación de abajo arriba) (Matland, 1995) son relevantes. La discrecionalidad ayuda a los implementadores a responder al contexto político e institucional. El contexto holandés es más abierto a la discrecionalidad y está más dispuesto a conseguir los objetivos políticos dada la facilidad con la que se pueden hacer cambios en los contratos, por ejemplo. No es así en el caso español, donde el principio de legalidad parece reinar sobre las metas políticas (Parrado y Reynaers, 2019). Como en el trabajo de Thomann et al. (2016), nuestro análisis de siete casos de estudio ofrece ejemplos donde hay un choque entre las lógicas del Estado y del mercado con escaramuzas de un agente privado para evitar el control estatal. Dada la complejidad de la fórmula financiera para establecer el contrato DCFOM, a veces ese control parece ser débil. Para los formuladores de políticas públicas hay una necesidad considerable de realzar el control de los agentes privados. El uso de consultores externos, la falta de experiencia financiera y el uso de mecanismos de autorreporte (casos holandeses) se deben considerar al tratar de salvaguardar los valores públicos. Además, los formuladores de políticas públicas y los implementadores públicos necesitan ser conscientes de que este instrumento político requiere una implementación cuidadosa y un monitoreo constante, pues el contrato carece de medidas propias para obligar su cumplimiento. Gิㅛ

\section{REFERENCIAS}

Acar, M. y P. Robertson (2004), "Accountability Challenges in Networks and Partnerships: Evidence from Educational Partnerships in the United States", International Review of Administrative Sciences, 70(2), pp. 331-344.

Alonso, J.M. y R. Andrews (2016), "How Privatization Affects Public Service Quality: An Empirical Analysis of Prisons in England and Wales, 1998-2012", International Public Management Journal, 19(2), pp. 235-263.

Altshuler, A. y D. Luberoff (2003), Mega-projects: The Changing Politics of Urban Public Investment, Washington, D.C., Brookings Institute Press.

Andaleeb, S.S. (2000), "Service Quality in Public and Private Hospitals in Urban Bangladesh: A Comparative Study”, Health Policy, 53(1), pp. 25-37. 
Andrews, R. y S. Van de Walle (2012), "New Public Management and Citizens' Perceptions of Local Service Efficiency, Responsiveness, Equity and Effectiveness", documento de trabajo 7, Cocops.

Aucoin, P. y M.D. Jarvis (2005), Modernizing Government Accountability: A Framework for Reform, Ottawa, Canada School of Public Service.

Beck Jørgensen, T. y B. Bozeman (2002), "Public Values Lost? Comparing Cases on Contracting out from Denmark and the United States", Public Management Review, 4(1), pp. 63-81.

Beck Jørgensen, T. y B. Bozeman (2007), "Public Values: An Inventory”, Administration and Society, 39(3), pp. 354-381.

Bevir, M. (2010), Democratic Governance, Princeton, Princeton University Press.

Bloomfield, P. (2006), "The Challenging Business of Long-Term Public-Private Partnerships: Reflections on Local Experience", Public Administration Review, 66(3), pp. 400-411.

Bovaird, T. y E. Löffler (2003), "Evaluating the Quality of Public Governance: Indicators, Models and Methodologies", International Review of Administrative Sciences, 69(3), pp. 313-328.

Bovaird, T. (2004), "Public-private Partnerships: From Contested Concepts to Prevalent Practice”, International Review of Administrative Sciences, 70(2), pp. 199-215.

Bovens, M. (2007), "Analysing and Assessing Accountability: A Conceptual Framework, European Law Journal, 13(4), pp. 447-468.

Box, R. (1999), "Running Government Like A Business. Implications for Public Administration Theory and Practice", American Review of Public Administration, 29(1), pp. $19-43$.

Brown, T., M. Potoski y D. Van Slyke (2006), "Managing Public Service Contracts: Aligning Values, Institutions, and Markets”, Public Administration Review, 66(3), pp. 323-331.

Brown, T., M. Potoski y D. Van Slyke (2007), "Trust and Contract Completeness in the Public Sector”, Local Government Studies, 33(4), pp. 607-623.

Brown, T., M. Potoski y D. Van Slyke (2010), "Contracting for Complex Products", Journal of Public Administration Research and Theory, 20(1), pp. i41-i58.

Carpenter, D., y G. Krause (2014), "Transactional Authority and Bureaucratic Politics", Journal of Public Administration Research and Theory, 25(1), pp. 5-25.

Child, J., D. Faulkner y S. Tallman (2005), Cooperative Strategy, Nueva York, Oxford University Press.

Collins, N. y P. Butler (2003), "When Marketing Models Clash with Democracy", Journal of Public Affairs, 3(1), pp. 52-62.

Considine, M. y J.M. Lewis (1999), "Governance at Ground Level: The Frontline Bureaucrat in the Age of Markets and Networks", Public Administration Review, 59(6), pp. 467-480. 
Davis, J., F. Schoorman y L. Donaldson (1997), “Toward a Stewardship Theory of Management", Academy of Management Review, 22(1), pp. 20-47.

De Bettignies, J.E. y T. Ross (2009), "Public-Private Partnerships and Privatization of Financing: An Incomplete Contracts Approach", International Journal of Industrial Organization, 27, pp. 358-368.

De Graaf, G. y H. Paanakker (2015), "Good Governance: Performance Values and Procedural Values in Conflict", The American Review of Public Administration, 45(6), pp. 635-652.

Deakin, N. y K. Walsh (1996), "The Enabling State: The Role of Markets and Contracts”, Public Administration, 74(1), pp. 33-47.

Debicki, M. (2003), "Public Service in a Corporate World: The Dangers of Managerialism as a Tool for Public Administration", en J. Finlay y M. Debicki (eds.), Delivering Public Services in Central and Eastern European Countries: Trends and Developments, Bratislava, NisPacee, pp. 27-36.

Domberger, S. y P. Jensen (1997), "Contracting out by the Public Sector: Theory, Evidence, Prospects", Oxford Review of Economic Policy, 13(4), pp. 67-78.

Eisenhardt, K. (1989), "Agency Theory: An Assessment and Review", Academy of Management Review, 14(1), pp. 57-74.

Eisenhardt, K.M. y M.E. Graebner (2007), “Theory Building from Cases: Opportunities and challenges", Academy of Management Journal, 50(1), pp. 25-32.

Flinders, M. (2010), "Splintered Logic and Political Debate", en G. Hodge, C. Greve y A. Boardman (eds.), International Handbook on Public-Private Partnerships, Northampton, Edward Elgar, pp. 115-131.

Frederickson, G. (1999), "Ethics and the New Managerialism", Public Administration \& Management: An Interactive Journal, 4(2), pp. 299-324.

Fumagalli, E., P. Garrone y L. Grilli (2007), "Service Quality in the Electricity Industry: The Role of Privatization and Managerial Behavior", Energy Policy, 35(12), pp. 62126224.

Garrow, E.E. y O. Grusky (2012), "Institutional Logic and Street-level Discretion: The Case of HIv Test Counseling", Journal of Public Administration Research and Theory, 23(1), pp. 103-131.

Guest, G., A. Bunce y L. Johnson (2006), "How Many Interviews are Enough? An Experiment with Data Saturation and Variability", Field Methods, 18(1), pp. 59-82.

Hartley, K. y M. Huby (1986), "Contracting-out Policy: Theory and Evidence”, en J.A. Kay, C. Mayer y D. Thompson (eds.), Privatisation and Regulation: The UK Experience, Nueva York, Oxford University Press, pp. 284-293.

Havinga, T. y P. Verbruggen (2017), "Understanding Complex Governance Relationships 
in Food Safety Regulation: The RIT Model as a Theoretical Lens", The Annals of the American Academy of Political and Social Science, 670(1), pp. 58-77.

Hill, C.W. y T.M. Jones (1992), "Stakeholder-agency Theory", Journal of Management Studies, 29(2), pp. 131-154.

Hirsch, W. y E. Osborne (2000), "Privatization of Government Services: Pressure Group Resistance and Service Transparency”, Journal of Labor Research, 21(2), pp. 315-326.

Hodge, G. (2004), "The Risky Business of Public-private Partnerships", Australian Journal of Public Administration, 63(4), pp. 37-49.

Hodge, G.A. y C. Greve (2017), "On Public-private Partnership Performance: A Contemporary Review”, Public Works Management \& Policy, 22(1), pp. 55-78.

Hodge, G. y C. Greve (2007), "Public-Private Partnerships: An International Performance Review”, Public Administration Review, 6(3), pp. 545-558.

Hodge, G. y K. Coghill (2007), "Accountability in the Privatized State", Governance, 20(4), pp. 675-702.

Holmstrom, B. y P. Milgrom (1991), "Multitask Principal-agent Analyses: Incentive Contracts, Asset Ownership, and Job Design”, Journal of Law, Economics, and Organization, 7, pp. 24-52.

Hood, J. y N. McGarvey (2002), "Managing the Risks of Public-private Partnerships in Scottish local government”, Policy Studies, 23(1), pp. 21-35.

Hood, J., I. Fraser y N. McGarvey (2006), "Transparency of Risk and Reward in UK Publicprivate Partnerships", Public Budgeting and Finance, 26(4), pp. 40-58.

Howlett, M. (2019), "Moving Policy Implementation Theory Forward: A Multiple Streams/ Critical Juncture Approach", Public Policy and Administration, 34(4), pp. 405-430.

Jensen, P.H. y R.E. Stonecash (2005), "Incentives and the Efficiency of Public Sector-outsourcing Contracts", Journal of Economic Surveys, 19(5), pp. 767-787.

Jessop, B. (2014), "Repoliticising Depoliticisation: Theoretical Preliminaries on Some Responses to the American Fiscal and Eurozone Debt Crises", Policy \& Politics, 42(2), pp. 207-223.

Jørgensen, T.B. y B. Bozeman (2007), "Public Values: An Inventory", Administration \& Society, 39(3), pp. 354-381.

Kiewiet, D. y M. McCubbins (1991), The Logic of Delegation, Chicago, University of Chicago Press.

King, S. y R. Pitchford (1998), "Privatization in Australia: Understanding the Incentives in Public and Private Firms", Australian Economic Review, 31(4), pp. 313-328.

Koppell, J.G. (2010), "Administration without Borders", Public Administration Review, 70, pp. s46-s55.

Lohmann, C. y P.G. Rötzel (2018), “The Outcome of Renegotiations between Institutionalized Public-Private Partnerships and Their Public Clients: Data on the Public-Pri- 
vate Partnerships of the German Federal Armed Forces", International Journal of Public Administration, 41(9), pp. 735-745.

Matland, R.E. (1995), "Synthesizing the Implementation Literature: The AmbiguityConflict Model of Policy Implementation”, Journal of Public Administration Research and Theory, 5(2), pp. 145-174.

McGuire, M. y R. Agranoff (2011), "The Limitations of Public Management Networks", Public Administration, 89(2), pp. 265-284.

Moe, T.M. (1989), "The Politics of Bureaucratic Structure", en J.E. Chubb y P.E. Peterson (eds.), Can the Government Govern?, Washington, D.C., Brookings Institution, pp. 267-329.

Mulgan, R. (1997), "Contracting out and Accountability", Australian Journal of Public Administration, 56(4), pp. 106-116.

Mulgan, R. (2003), Holding Power to Account: Accountability in Modern Democracies, Londres, Palgrave Macmillan.

Mulgan, R. (2003), Holding Power to Account: Accountability in Modern Democracies, Londres, Palgrave Macmillan.

Nabatchi, T. (2012), "Putting the 'Public' Back in Public Values Research: Designing Participation to Identify and Respond to Values", Public Administration Review, 72(5), pp. 699-708.

Papadopoulos, Y. (2007), "Problems of Democratic Accountability in Network and Multilevel Governance”, European Law Journal, 13(4), pp. 469-486.

Parrado, S. y A. Reynaers (2019), "Public-Private Partnerships: Procedural-Over ResultsDriven Accountability”, International Review of Administrative Sciences, DoI: 10.1177/ 0020852319864161.

Peat, B. y D. Costley (2001), "Effective Contracting of Social Service", Nonprofit Management and Leadership, 12(1), pp. 55-74.

Pressman, J. y A. Wildavsky (1984), Implementation, 3a. ed., Berkeley, University of California Press.

Reynaers, A. y G. de Graaf (2014), "Public Values in Public-Private Partnerships", International Journal of Public Administration, 37(2), pp. 120-128.

Reynaers, A. y S. Grimmelikhuijsen (2015), "Explaining Transparency in Public-Private Partnerships: Not so bad after all?", Public Administration, 93(3), pp. 609-626.

Reynaers, A. (2014), "Public Values in Public Private-Partnerships", Public Administration Review, 74(1), pp. 41-50.

Reynaers. A. (2019), "Mission Impossible for Effectiveness? Service Quality in Publicprivate Partnerships", en H. Paanakker, A. Masters y L. Huberts (eds.), Quality of Governance: Values and Violations, Cham, Palgrave Macmillan, Dor:10.1007/978-3030-21522-4. 
Rosenau, P. (2000), The Strengths and Weaknesses of Public-Private Policy Partnerships, Cambridge: The MIT Press.

Skelcher, C. y S. Smith (2015), "Theorizing Hybridity: Institutional Logics, Complex Organizations, and Actor Identities: The Case of Nonprofits", Public Administration, 93(2), pp. 433-448.

Skelcher, C. (2010), “Governing Partnerships”, en G. Hodge, C. Greve y A. Boardman (eds.), International Handbook on Public-Private Partnerships, Northampton, Edward Elgar, pp. 292-306.

Skelcher, C., N. Mathur y M. Smith (2005), "The Public Governance of Collaborative Spaces: Discourse, Design and Democracy”, Public Administration, 83(3), pp. 573-596. Thomann, E., P. Hupe y F. Sager (2018), "Serving Many Masters: Public Accountability in Private Policy Implementation”, Governance, 31(2), pp. 299-319.

Thomann, E., E. Lieberherr y K. Ingold (2016), “Torn between State and Market: Private Policy Implementation and Conflicting Institutional Logics", Policy and Society, 35(1), pp. 57-69.

van der Wal, Zeger (2008), "Value Solidity: Differences, Similarities, and Conflicts Between the Organizational Values of Government and Business", tesis doctoral, Universidad Libre de Ámsterdam-Departamento de Ciencias Sociales.

Van Slyke, D. y C. Hammonds (2003), "The Privatization Decision: Do Public Managers Make a Difference?”, The American Review of Public Administration, 33(2), pp. 146-163. Wang, H., W. Xiong, G. Wu y D. Zhu (2018), "Public-private Partnership in Public Administration Discipline: A Literature Review”, Public Management Review, 20(2), pp. 293-316.

Willems, T. (2014), "Democratic Accountability in Public-private Partnerships: The Curious Case of Flemish School Infrastructure”, Public Administration, 92(2), pp. 340-358.

Willems, T. y W. Van Dooren (2016), “(De)Politicization Dynamics in Public-private Partnerships (pPps): Lessons from a Comparison between the UK and Flemish PPP Policy", Public Management Review, 18(2), pp. 199-220. 


\section{APÉNDICE 1. GUÍA DE ENTREVISTAS}

\section{General}

1. ¿Cuál es o fue su papel en este proyecto? ¿En qué fases del proyecto estuvo involucrado?

2. ¿Cuál es su bagaje profesional?

3. ¿Cuántos años de experiencia tiene con este tipo de concesiones?

\section{Rendición de cuentas}

1. ¿Nos podría decir quién le rinde cuentas a quién en este proyecto? (Entre la administración y la concesionaria, dentro de la compañía, fuera de la compañía).

2. ¿Sobre qué aspectos usted/ellos tienen que rendir cuentas?

3. ¿Cómo tiene que explicar los gastos del proyecto?

4. ¿Ha tenido algún problema en el proceso?

5. ¿Podría explicarlo y dar ejemplos?

6. ¿Nos podría decir cómo funciona la gestión financiera del proyecto?

7. ¿Cómo rinde cuentas sobre los acuerdos contractuales y sus adaptaciones?

8. ¿Ha tenido algún problema durante el proceso?

9. ¿Podría explicarlo y dar ejemplos?

10. ¿Nos podría decir cómo funcionan los acuerdos contractuales y sus adaptaciones?

11. ¿Cómo explica las especificaciones del producto y sus adaptaciones?

12. ¿Ha tenido algún problema durante el proceso?

13. ¿Podría explicarlo y dar ejemplos?

14. ¿Nos podría decir cómo funcionan las especificaciones del producto y sus adaptaciones?

15. ¿Cómo rinde cuentas por el desempeño en la fase de construcción y en la fase operativa?

16. ¿Ha tenido algún problema durante el proceso?

17. ¿Podría explicarlo y dar ejemplos?

18. ¿Nos podría decir cómo se usa la información sobre el desempeño?

19. ¿Tiene la impresión de poder seguir el proceso? ¿En qué sentido?

\section{Transparencia}

1. ¿Cómo organizó el proceso de formulación de especificaciones financieras y técnicas? 
2. ¿En qué grado cooperó con el consorcio/ministerio durante el proceso?

3. ¿Ha tenido algún problema durante el proceso?

4. ¿Está satisfecho con la cantidad y calidad de la información que aparece en el contrato?

5. ¿Cómo está organizado el proceso de formulación de especificaciones del producto?

6. ¿Ha tenido algún problema durante el proceso?

7. ¿En qué grado cooperó con la concesionaria/administración durante el proceso?

8. ¿Está satisfecho con la cantidad y calidad de la información sobre los estándares de los resultados?

9. ¿Cómo organizó el proceso de seguimiento en las fases de implementación y operación del proyecto?

10. ¿En qué grado cooperó con la concesionaria/administración durante el proceso?

11. ¿Ha tenido algún problema durante el proceso?

12. ¿Está satisfecho con la cantidad y calidad de la información brindada?

13. ¿Qué tan útiles fueron las especificaciones del contrato y del producto?

14. ¿Ha tenido algún problema durante en este respecto?

\section{Capacidad de respuesta}

1. ¿Quién decide los acuerdos contractuales?

2. ¿Cómo se organizó este proceso?

3. Según usted, ¿’hubo suficiente participación de los interesados?

4. ¿Quién decide las especificaciones del producto?

5. ¿Cómo se organizó el proceso?

6. Según usted, ¿hubo suficiente participación de los actores clave?

7. ¿Acaso el ministerio o el consorcio trató de ajustar las especificaciones del producto o los acuerdos contractuales durante el proyecto?

8. ¿En qué grado usted fue capaz de hacerlo? Si fue difícil, ¿qué lo dificultó?

9. ¿Quién cree usted que está a cargo del proyecto?

\section{Cumplimiento del contrato}

1. ¿Cuál es su impresión general del esfuerzo que hizo el consorcio?

2. Según usted, ¿el consorcio provee lo que debe proveer?

3. Si es así, ¿puede dar ejemplos?

4. ¿Por qué cree que proveen lo que deben? 
5. Si no, ¿puede dar ejemplos?

6. ¿Por qué cree que no proveen lo que deben?

7. ¿Hay disputas entre el consorcio y el ministerio sobre si el consorcio hace lo que debe hacer? Si es así, ¿¿cuáles son los temas de las disputas?

\section{Calidad}

1. ¿Cuál es su opinión sobre la calidad de la infraestructura?

2. ¿Puede explicarlo?

3. ¿Puede dar ejemplos?

4. Comparado con sus experiencias previas, ¿`ómo considera la calidad de la infraestructura en este proyecto?

5. ¿Cuál es su opinión sobre la calidad del suministro de servicios?

6. ¿Puede explicarlo?

7. ¿Puede dar ejemplos?

8. Comparado con sus experiencias previas, ¿cómo considera la calidad del suministro de servicios en este proyecto?

9. ¿Está contento con él?

10. ¿Con qué aspectos está menos contento? 


\section{APÉNDICE 2. CÓDIGOS USADOS PARA ANALIZAR LAS ENTREVISTAS}

Rendición de cuentas

- Contenido (Financiero/Legal/Técnico)

- Desempeño (Construcción/Servicios)

\section{Transparencia}

- Antes del cierre del contrato -Disponibilidad de información (Financiero/Legal/Técnico/Operativo) -Acceso a la información (Financiero/Legal/Técnico/Operativo) -Precisión de la información (Financiero/Legal/Técnico/Operativo)

- Después del cierre del contrato -Disponibilidad de información (Financiero/Legal/Técnico/Operativo) -Acceso a la información (Financiero/Legal/Técnico/Operativo) -Precisión de la información (Financiero/Legal/Técnico/Operativo)

Capacidad de respuesta

- Antes del cierre del contrato (Definir/Influir/Adaptar)

- Después del cierre del contrato (Definir/Influir/Adaptar)

Cumplimiento del contrato

- Se cumplió

- No se cumplió

Calidad

- Calidad de la infraestructura (Satisfecho/No satisfecho)

- Calidad de los servicios (Satisfecho/No satisfecho) 
Salvador Parrado enseña asignaturas vinculadas a la administración pública en la Universidad Nacional de Educación a Distancia (Madrid). Ha sido investigador visitante de las siguientes universidades: Bamberg, Hertie School of Governance (Berlín) y Universidad Libre de Berlín (Alemania), Universidad de Leicester y Central Lancashire (Reino Unido), Alexandru Ioan Cuza de Iasi (Rumanía) y Sabanci (Turquía). Ha investigado de forma comparada el poder ejecutivo, los sistemas administrativos, la gestión pública, la regulación del riesgo, los valores públicos, las asociaciones público-privadas y el servicio civil. Ha publicado quince libros solo o en coautoría sobre estos temas y más de 50 artículos y capítulos de libros en revistas y editoriales de prestigio. Es director fundador de Governance International (www.govint.org) y fue editor asociado de Public Administration (https://goo.gl/koLXc5) desde 2011 hasta 2020.

Anne-Marie Reynaers es profesora ayudante doctora en el Departamento de Ciencia Política y Relaciones Internacionales de la Universidad Autónoma de Madrid. Desde 2014 es doctora en Ciencias de la Administración por la Universidad Libre de Ámsterdam (Países Bajos). Realizó un máster en Investigación en Ciencias de la Administración y de la Organización en la Universidad de Utrecht (Países Bajos), y es licenciada en Ciencias de la Administración (Universidad de Tilburg, Países Bajos). Ha completado su formación con cursos especializados en técnicas de investigación organizados por la Universidad de Essex (Reino Unido) y la Universidad de Roskilde (Dinamarca). Su investigación aborda temas como la gestión pública, la externalización, los consorcios público-privados, los valores públicos, la gestión hospitalaria, las reformas del sector público, la regulación, la gestión de contratos, la privatización y el seguimiento del desempeño. 